\title{
Pleomorphic Adenoma Consisting of Multiple Cysts with Squamous Epithelial Lining: Findings on MRI, FNAC, and Histopathological Examination
}

\author{
Hiroshi Yamamoto', Sakurako Yamaguchi', Erika Iwai', Yukiko Iizuka1, Shu Fushimi',

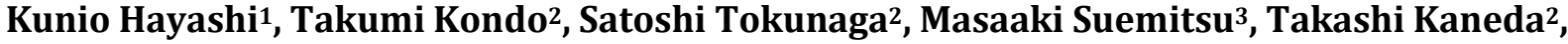 \\ Kayo Kuyama ${ }^{3}$, Masamichi Komiya ${ }^{1}$
}

\footnotetext{
${ }^{1}$ Department of Oral Surgery, Nihon University School of Dentistry at Matsudo, Chiba, Japan

${ }^{2}$ Department of Radiology, Nihon University School of Dentistry at Matsudo, Chiba, Japan

${ }^{3}$ Department of Pathology, Nihon University School of Dentistry at Matsudo, Chiba, Japan

Email: yamamoto.hiroshi16@nihon-u.ac.jp
}

\begin{abstract}
How to cite this paper: Yamamoto, $\mathrm{H}$., Yamaguchi, S., Iwai, E., Iizuka, Y., Fushimi, S., Hayashi, K., Kondo, T., Tokunaga, S., Suemitsu, M., Kaneda, T., Kuyama, K. and Komiya, M. (2021) Pleomorphic Adenoma Consisting of Multiple Cysts with Squamous Epithelial Lining: Findings on MRI, FNAC, and Histopathological Examination. Open Journal of Stomatology, 11, 221-230. https://doi.org/10.4236/ojst.2021.116019
\end{abstract}

Received: May 11, 2021

Accepted: June 15, 2021

Published: June 18, 2021

Copyright $\odot 2021$ by author(s) and Scientific Research Publishing Inc. This work is licensed under the Creative Commons Attribution International License (CC BY 4.0)

http://creativecommons.org/licenses/by/4.0/

(c) (i) Open Access

\begin{abstract}
The incidence of pleomorphic adenoma (PA) of the minor salivary glands is reported to be $10 \%$, and while the histological findings in PA can be diverse, keratin-filled cysts lined by squamous epithelium are rarely reported. The condition can, however, present with cyst formation in some cases. We review a rare case of pleomorphic adenoma in the buccal mucosa that involved the formation of multiple squamous epithelium-lined cysts in a 69-year-old woman. Magnetic resonance imaging (MRI), fine needle aspiration cytology, and histopathological examination were performed. Physical examination revealed a painless, mobile, elastic hard mass in the right buccal mucosa, measuring $2.5 \times 1.0 \mathrm{~cm}$. The MRI revealed a well-defined lesion with different signal intensities in the medial and distal regions of the right cheek. The medial side of the lesion showed a low signal intensity on T1-weighted imaging (T1WI) and T2-weighted imaging (T2WI), while the distal side showed a low signal intensity on T1WI, and a high signal intensity on T2WI and short tau inversion recovery (STIR) imaging. Fine needle aspiration of the lesion was performed under local anesthesia and a cytological diagnosis of an epidermoid or dermoid cyst was made. The tumor was completely resected under local anesthesia combined with intravenous sedation. The histopathological examination demonstrated the proliferation of atypical tumor cells with poor atypia and the formation of glandular, alveolar, large, and small cysts. The cysts were lined by keratinized squamous epithelial cells, their cavities were filled with keratinous material, and foreign body reaction was observed
\end{abstract}


after rupture. Histopathological evaluation led to the diagnosis of pleomorphic adenoma. The patient had no evidence of recurrence, 2 years and 3 months after the surgery. In conclusion, the presence of multiple cysts lined by squamous epithelium can pose a significant diagnostic challenge in patients with PA. It is important to make the correct diagnosis in order to avoid unnecessarily aggressive therapy.

\section{Keywords}

Salivary Gland Tumor, Pleomorphic Adenoma, Cystic Formation

\section{Introduction}

Pleomorphic adenoma (PA) is the most common benign tumor of the major and minor salivary glands. The parotid gland is the most common site of PA. The incidence of PA of the minor salivary glands is reported to be $10 \%$ [1]. The minor salivary glands located in the hard palate $(42.8 \%-68.8 \%)$ are the most commonly affected, followed by those in the upper lip (10.1\%) and then the ones in the buccal mucosa (5.5\%) [2]. Clinically, it presents as a slow growing, painless, sessile and firm mass which may or may not have an ulcerated surface.

Histologically, PA is characterized by a wide spectrum of morphological patterns, including squamous cells, mucous cells, oncocytes, sebaceous cells, bone tissue, adipose tissue, and crystalline material [3]. It is composed of a mixture of glandular epithelium and myoepithelial cells within a mesenchyme-like tissue, and the proportion of each component varies widely among individual tumors. The histomorphological variations are so extensive that in an incisional biopsy specimen, diagnosis can be challenging. Extensive keratin-filled cysts lined by squamous epithelium are a rarely reported phenomenon in PA. We present an unusual case of PA of the buccal mucosa with the formation of multiple squamous epithelium-lined cysts, accompanied by magnetic resonance imaging (MRI), fine needle aspiration cytology, and histopathological investigations. Informed consent was obtained from all individuals included in the study. All procedures performed in studies involving human participants were in accordance with the ethical standards of the Committee on Studies Involving Human Beings of Nihon University School of Dentistry at Matsudo (EC-20-19-023-1) and with the 1964 Declaration of Helsinki and its later amendments or comparable ethical standards.

\section{Case Report}

A 69-year-old woman presented with the complaint of a mass that had grown slowly in size over the previous 8 months in the right buccal mucosa. She had no past history of surgery, trauma, or infection of the buccal mucosa. There was a past medical history of cerebral infarction, hypertension, diabetes, and nephrolithiasis. Physical examination revealed hypoesthesia of the right lower lip and 
no facial asymmetry. On intraoral examination, a mass measuring approximately $2.5 \mathrm{~cm} \times 1.0 \mathrm{~cm}$ was observed in the right buccal mucosa. The lesion was well-defined, peanut-like in form, movable, painless, and elastic hard. There were no associated palpable lymph nodes (Figure 1). Fine needle aspiration of the lesion was performed under local anesthesia; an epidermoid or dermoid cyst was suspected after cytological findings. A provisional diagnosis of epidermoid cyst was made because the differential diagnoses included a benign salivary gland tumor. The lesion was completely resected under local anesthesia combined with intravenous sedation. There was no evidence of recurrence in the patient over a postoperative follow-up period of 2 years and 3 months.

\section{- MRI findings}

She MRI scan revealed a well-defined lesion in the right cheek, with different signal intensities in its medial and distal regions. The medial side of the lesion showed a low signal intensity on T1-weighted imaging (T1WI), T2-weighted imaging (T2WI), and short tau inversion recovery (STIR) imaging, while the distal side of the lesion showed a low signal intensity on T1WI, and a high signal intensity on T2WI and STIR imaging (Figure 2).

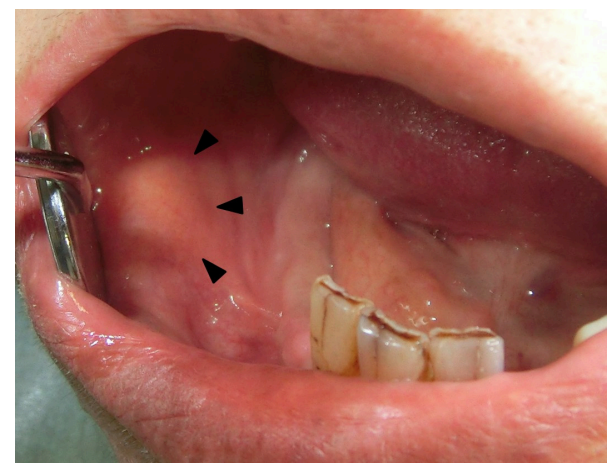

Figure 1. Photograph of the initial intraoral examination showing a well-defined and elastically hard mass (arrow head) in the right buccal mucousa.

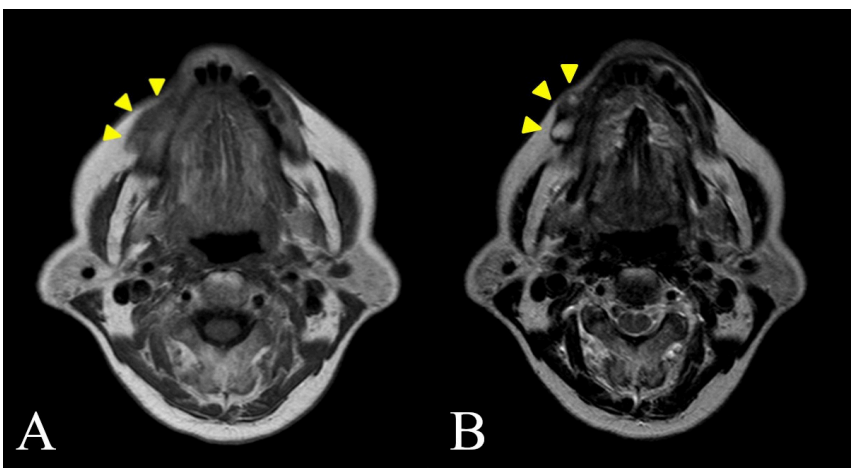

Figure 2. A: Magnetic resonance imaging showed the lesion (arrow head) showed a well-defined low signal intensity area on T1WI. B: There is a low signal intensity on mesial side of the lesion, and the distal side showed a high signal intensity on T2WI (arrow head). 


\section{- Cytological Findings}

Alcohol-fixed direct smears were stained with the standard Papanicolaou stain. A cluster of keratin debris was seen (Figure 3A), and epithelial cells with keratohyalin granules and agglomerates of epithelial cells that were about to be enucleated were observed by higher magnification (Figure 3B). No atypical cells were found, and a cytological diagnosis of the epidermoid cyst was made.

- Gross and Histopathological findings

The resected specimen comprised of an encapsulated soft tissue mass measuring $2.3 \mathrm{~cm} \times 1.2 \mathrm{~cm} \times 1.0 \mathrm{~cm}$. The mass was elastic and slightly hard, and its cut surface was firm and brown to yellowish white in color.

Histopathological examination of hematoxylin and eosin-stained sections revealed that the lesion was mostly covered with a fibrous capsule; one side of the nodule was cystic, while the other bore numerous cysts consisting of epithelial tumor cells (Figure 4A). In certain parts of the tumor, a foreign body reaction following rupture was observed. The tumor cells were structured in a tubular manner similar to that of glands, and an eosinophilic glass-like substance was present in the glandular cavity. The duct-like formations consisted of ductal luminal cells in the inner layer and myoepithelial-like cells in the outer layer (Figure 4B). The ductal structures occurred in variable sizes and shapes. Within some epithelial nests, foci of squamous metaplasia with keratohyalin granules were found. The cavities were filled with keratin debris (Figure 4C). The cystic cavities and tumor stroma contained calcified foci in some areas (Figure 4D). The tumor cells with a ductal structure and those with a cystic cavity were continuous with one another (Figure 4E). No intracapsular invasion or atypical cell was observed. The pathological diagnosis was pleomorphic adenoma with formation of multiple cysts with squamous epithelium lining.

\section{Discussion}

PA accounts for $54 \%-65 \%$ of all salivary gland neoplasms and $80 \%$ of all benign salivary gland tumors [4]. PA frequently occurs frequently in the minor salivary glands located in the palate, and rarely in those located in the buccal mucosa. Various studies have reported different incidences of PA of the minor salivary glands of the cheek (Table 1) [5] [6] [7] [8]. In this case, the tumor was located on the side of the buccinator muscle facing the oral cavity in the right buccal mucosa, suggesting that the tumor was derived from the buccal glands.

A

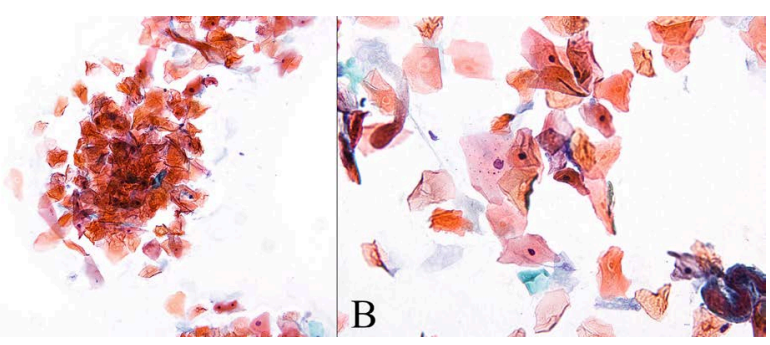

Figure 3. A: A cluster of squamous cells and horny substances. FNA (Pap. staining, $\times 20)$ B: Epithelial cells about to enucleate. FNA (Pap. staining, $\times 40$ ). 


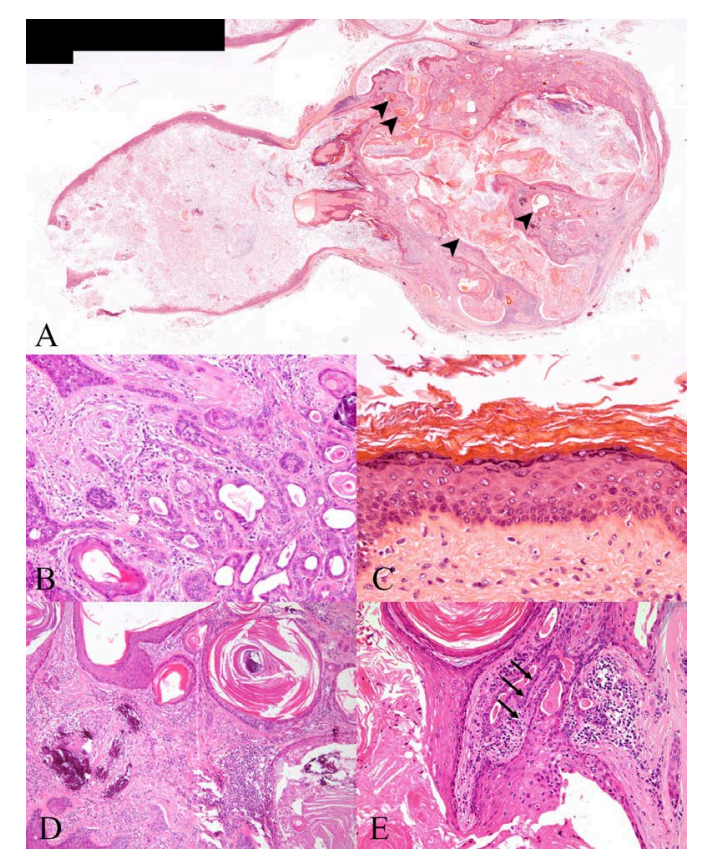

Figure 4. A: Large and small cyst formation. (arrow head) (H. E. staining, Gross) B: Higher power view of the tumor epithelial cells and duct-like structures, and myoepithelial-like cells in the outer layer. (H. E. staining, $\times 10$ ) C: The cystic wall lined with a hyperkeratinized squamous epithelium with keratohyalin granules. (H. E. staining, $\times 40$ ) D: Large and small cysts covered by hyperkeratinized squamous epithelium were keratin-filled. (H. E. staining, $\times 10) \mathrm{E}$ : Tumor cells with ductal structure and cystic cavity are continuous. (arrow) (H. E. staining, $\times 10$ )

Table 1. Literature review of the frequency of pleomorphic adenoma of the minor salivary glands of the cheek.

\begin{tabular}{ccccc}
\hline Author & Year & $\begin{array}{c}\text { Total number of } \\
\text { pleomorphic } \\
\text { adenoma cases }\end{array}$ & $\begin{array}{c}\text { Number of cases Percentage (\%) of } \\
\text { in cheek }\end{array}$ & cases in cheek \\
\hline Chaudhry, A.P., et al. [5] & 1961 & 476 & 38 & 8 \\
Isacsson, G. and Shear, M. [6] & 1983 & 140 & 7 & 5 \\
Cohen, M.A. [7] & 1986 & 144 & 10 & 7 \\
Buchner, A., et al. [8] & 2007 & 149 & 19 & 13 \\
\hline
\end{tabular}

Past reports of PA accompanied by the formation of multiple squamous epithelium-lined cysts are listed in Table 2 [9] [10]-[24]. Several mechanisms of cyst formation in PA have also been suggested. Devgan, et al. [25] described that an etiology involving squamous metaplasia of the tumor cells and central necrosis followed by well-defined differentiation of the epithelium, was responsible for cyst formation. Hamdan, et al. [26] reported that ischemia could lead to the metaplastic changes in PA. Goulart, et al. [15] suggested that the exposure of minor salivary gland ductal epithelium to different irritants could play a significant role in the formation of keratin pearls. Lucas [27] described that cyst formation was 
Table 2. Reported cases of pleomorphic adenoma with formation of multiple squamous epithelium-line cysts.

\begin{tabular}{ccc}
\hline Author & Year & Location \\
\hline Abiko, Y., et al. [9] & 1993 & palatal gland \\
Lam, K.Y., et al. [3] & 1998 & plate \\
Stewart, C.J.R., et al. [10] & 2000 & minor salivary gland \\
Aker, H., et al. [11] & 2003 & buccal mucosa \\
Brachtel, E.F., et al. [12] & 2003 & parotid gland \\
Batrani, M., et al. [13] & 2008 & buccal mucosa \\
Siddaraju, N., et al. [14] & 2009 & submandibular gland \\
Goulart, M.C., et al. [15] & 2009 & upper vestibule \\
Kaveri, H., et al. [16] & 2014 & palate \\
Reddy, V., et al. [17] & 2015 & retromolar trigone \\
Brisebois, S., et al. [18] & 2015 & palate \\
Jaishankar, H.P., et al. [19] & 2016 & palate \\
Sreelatha, S.V., et al. [20] & 2017 & buccal mucosa \\
Tandon, A., et al. [21] & 2018 & palate \\
Sharma, S., et al. [22] & 2018 & palate \\
Anjum, R., et al. [23] & 2019 & buccal mucosa \\
Urs, A.B., et al. [23] & 2019 & \\
& & lip \\
& &
\end{tabular}

associated with degeneration of the layer of tumor tissue containing hemorrhage. It has been reported that necrotic lesions may give rise to cysts in polymorphic adenomatous carcinoma [9]. Similar to Abiko, et al. [9], we assumed that the cysts in this case were formed due to the degeneration of squamous metaplasia of the tumor cells, owing to the following reasons: the lining epithelium was continuous with the tumor cells, the cyst wall consisted of hyperkeratinized squamous epithelium, and a large amount of keratinized material was stored within the cysts.

Squamous metaplasia and keratin pears are not unusual [28]. However, keratin-filled cysts lined by squamous epithelium are a rare finding. PAs with extensive squamous metaplasia can signify a potential pitfall in the histopathological diagnosis.

Fine needle aspiration cytology (FNAC) is a widely accepted investigation for differentiating between benign and malignant tumors and for the histological evaluation of salivary gland tumors. Its diagnostic accuracy has been reported as $80 \%-95 \%$ in most series, provided that adequate and appropriately prepared materials are available [10] [29]. Despite its histologic diversity, PA can, in most cases, be easily diagnosed through cytological evaluation, due to its typical cytological appearance. The combination of bland epithelial cells and fragments of chondromyxoid stroma with spindle cells is very characteristic of this tumor 
[30]. However, in some cases, major variations from this common cytological pattern may result in an erroneous cytological diagnosis, and subsequently, in a different treatment or surgical approach to the tumor [30]. Foci of squamous cells are integral features of PA; nonetheless, extensive squamous metaplasia is uncommon and can be easily misinterpreted as squamous cell carcinoma, especially on FNAC, due to its limited and selective sampling [22].

In addition, the diagnosis of PA becomes challenging in the absence of chondromyxoid stroma, making it imperative to understand this diagnostic pitfall [31]. In this case, only epithelial cells with keratohyalin granules as well as clumps of epithelial cells that were about to be enucleated were observed; therefore, a presumptive diagnosis of PA was not made. Such an observation could be explained by the relatively large cyst structure, which could have prevented the puncture needle from reaching the tumor parenchyma. In the presence of a salivary gland tumor with cystic change, the differential diagnoses of Warthin tumor, basal cell adenoma, cystadenoma, mucoepidermoid carcinoma, acinic cell carcinoma, and cystadenocarcinoma were considered. Histopathologically, PA of the minor salivary glands is usually unencapsulated [32], and approximately $50 \%$ of tumors of the minor salivary glands are considered to be malignant [1] [33]. Histopathologically, differential diagnoses include simultaneous occurrence of PA and dermoid cysts.

Dermoid cysts usually have a clear stratum granulosum all around. In this case, there is a clear granular layer, but it is limited. The cyst wall consisted of hyperkeratinized squamous epithelium, the lining epithelium was continuous with the tumor cells. It is rare for dermoid cysts to form a large number of large and small cyst structures locally. Based on the findings above, the simultaneous occurrence of PA and dermoid cysts was considered to be unlikely.

It is necessary to consider a frozen section diagnosis, owing to the high rate of false negatives for malignancy in cystic tumors. Surgical resection of the tumor is generally used in the treatment of patients with PA. PA of the minor salivary glands is widely excised including the periosteum or bone because the tumor cells infiltrate the periosteum to either form a nodule or cause detachment of the periosteum from the underlying bone. Enucleation is not the treatment of choice, as it can lead to high local recurrence rate. In this case, the suspicion of a dermoid cyst on FNAC led to minimal excision of the surrounding healthy tissue. No recurrence was observed 2 years and 3 months after the operation but owing to the high recurrence rate of PA, long-term follow-up is necessary.

\section{Conclusion}

In conclusion, PA consisting of multiple cysts lined by squamous epithelium can pose a significant diagnostic challenge. It is important to bear this presentation in mind in order to distinguish PA from malignant lesions and to avoid unnecessarily aggressive therapy. A frozen section analysis should be considered because of the high rate of false negatives for malignancy in cystic tumors. 


\section{Acknowledgements}

This work was supported by JSPS KAKENHI Grant Number 19K19213.

\section{Conflicts of Interest}

The authors declare no conflicts of interest regarding the publication of this paper.

\section{References}

[1] Eveson, J.W. and Cawson, R.A. (1985) Salivary Gland Tumours. A Review of 2410 Cases with Particular Reference to Histological Types, Site, Age and Sex Distribution. The Journal of Pathology, 146, 51-58. https://doi.org/10.1002/path.1711460106

[2] Verma, P., Sachdeva, S.K., Verma, K.G. and Sachdeva, K. (2014) Pleomorphic Adenoma of Cheek: A Rare Case Report and Review of Literature. Indian Journal of Dental Research, 25, 122-124. https://doi.org/10.4103/0970-9290.131166

[3] Lam, K.Y., Ng, I.O. and Chan, G.S. (1998) Palatal Pleomorphic Adenoma with Florid Squamous Metaplasia: A Potential Diagnostic Pitfall. Journal of Oral Pathology \& Medicine, 27, 407-410. https://doi.org/10.1111/j.1600-0714.1998.tb01976.x

[4] Friedrich, R.E., Li, L., Knop, J., Giese, M. and Schmelzle, R. (2005) Pleomorphic Adenoma of the Salivary Glands: Analysis of 94 Patients. Anticancer Research, 25, 1703-1705.

[5] Chaudhry, A.P., Vickers, R.A. and Gorlin, R.J. (1961) Intraoral Minor Salivary Gland Tumors. An Analysis of 1,414 Cases. Oral Surgery, Oral Medicine, Oral Pathology, 14, 1194-1226. https://doi.org/10.1016/0030-4220(61)90209-2

[6] Isacsson, G. and Shear, M. (1983) Intraoral Salivary Gland Tumors: A Retrospective Study of 201 Cases. Journal of Oral Pathology \& Medicine, 12, 57-62.

https://doi.org/10.1111/j.1600-0714.1983.tb00316.x

[7] Cohen, M.A. (1986) Pleomorphic Adenoma of the Cheek. International Journal of Oral and Maxillofacial Surgery, 15, 777-779. https://doi.org/10.1016/S0300-9785(86)80123-5

[8] Buchner, A., Merrell, P.W. and Carpenter, W.M. (2007) Relative Frequency of Intra-Oral Minor Salivary Gland Tumors: A Study of 380 Cases from Northern California and Comparison to Reports from Other Parts of the World. Journal of Oral Pathology \& Medicine, 36, 207-214. https://doi.org/10.1111/j.1600-0714.2007.00522.x

[9] Abiko, Y., Kaku, T., Shimono, M., Noma, H. and Shigematsu, T. (1993) Large Cyst Formation in Pleomorphic Adenoma. The Bulletin of Tokyo Dental College, 34, 9-14.

[10] Stewart, C.J.R., MacKenzie, K., McGarry, G.W. and Mowat, A. (2000) Fine-Needle Aspiration Cytology of Salivary Gland: A Review of 341 Cases. Diagnostic Cytopathology, 22, 139-146. https://doi.org/10.1002/(SICI)1097-0339(20000301)22:3<139::AID-DC2>3.0.CO;2$\underline{\mathrm{A}}$

[11] Aker, H., Oztürk, M., Ozeç, I. and Ozer, H. (2003) An Unusual Buccal Adenoma with Extensive Squamous Metaplasia and Cyst Formation. Journal of the Chinese Medical Association, 66, 184-188.

[12] Brachtel, E.F., Pilch, B.Z., Khettry, U., Zembowicz, A. and Faquin, W.C. (2003) 
Fine-Needle Aspiration Biopsy of a Cystic Pleomorphic Adenoma with Extensive Adnexa-Like Differentiation: Differential Diagnostic Pitfall with Mucoepidermoid Carcinoma. Diagnostic Cytopathology, 28, 100-103. https://doi.org/10.1002/dc.10240

[13] Batrani, M., Kaushal, M., Sen, A.K., Yadav, R. and Chaturvedi. N.K. (2008) Pleomorphic Adenoma with Squamous and Appendageal Metaplasia Mimicking $\mathrm{Mu}$ coepidermoid Carcinoma on Cytology. CytoJournal, 6, 5. https://doi.org/10.4103/1742-6413.45496

[14] Siddaraju, N., Murugan, P., Basu, D. and Verma, S.K. (2009) Preoperative Cytodiagnosis of Cystic Pleomorphic Adenoma with Squamous Metaplasia and Cholesterol Crystals: A Case Report. Acta Cytological, 53, 101-104. https://doi.org/10.1159/000325093

[15] Goulart, M.C., Freitas-Faria, P., Goulart, G.R., Oliveira, A.M., Carlos-Bregni, R., Soares, C.T. and Lara, V.S. (2011) Pleomorphic Adenoma with Extensive Squamous Metaplasia and Keratin Cyst Formations in Minor Salivary Gland: A Case Report. Journal of Applied Oral Science, 19, 182-188. https://doi.org/10.1590/S1678-77572011000200016

[16] Kaveri, H., Gopalkrishnana, K. and Venkatesh, A. (2014) Cystic and Florid Squamous Metaplasia in Pleomorphic Adenoma of Palate-A Diagnostic Dilemma. Asian Journal of Medical Sciences, 5, 108-110. https://doi.org/10.3126/ajms.v5i4.10434

[17] Reddy, V., Wadhwan, V., Aggarwal, P., Sharma, P. and Reddy, M. (2015) A Benign Salivary Gland Tumor of Minor Salivary Gland Mimicking an Epithelial Malignancy. Contemporary Clinical Dentistry, 6, 247-249. https://doi.org/10.4103/0976-237X.156058

[18] Brisebois, S., Chababi, A.M., Borduas, M. and Fortier, P.H. (2015) A Challenging Case of Squamous Metaplasia in a Pleomorphic Adenoma: Diagnostic and Clinical Pitfalls. Journal of Surgical Case Reports, 2015, rjv113.

https://doi.org/10.1093/jscr/rjv113

[19] Jaishankar, H.P., Hegde, U. and Nagpal, B. (2016) Florid Squamous Metaplasia and Keratin Cyst Formation in Palatal Minor Salivary Gland Tumor: A Diagnostic Challenge. International Journal of Health Sciences and Research, 6, 516-520.

[20] Sreelatha, S.V., Chandra, J. and Bharathi, B.D. (2017) Florid Keratin Pearls in Pleomorphic Adenoma-A Mimicker to Malignancy. Journal of Medicine, Radiology, Pathology \& Surgery, 4, 16-19. https://doi.org/10.15713/ins.jmrps.113

[21] Tandon, A., Jaiswal, R., Siddiqui, S. and Bordoloi, B. (2018) Keratinizing Pleomorphic Adenoma: An Unusual Case Report. Journal of Oral and Maxillofacial Pathology, 22, 69-72. https://doi.org/10.4103/jomfp.JOMFP_200_17

[22] Sharma, S., Mehendiratta, M., Chaudhary, N., Gupta, V., Kohli, M. and Arora, A. (2018) Squamous Metaplasia in Pleomorphic Adenoma: A Diagnostic and Prognostic Enigma. Journal of Pathology and Translational Medicine, 52, 411-415. https://doi.org/10.4132/jptm.2018.07.15

[23] Anjum, R., Siraj, M.R., Tahir, T.M., Javed, M., Farrukh, K., Masood, M. and Naseem, N. (2019) Keratinizing Pleomorphic Adenoma in Minor Salivary Gland: A Case Report. Biomedica, 35, 191.

[24] Urs, A.B., Augustine, J., Negi, D., Kumar, R.D. and Ghosh, S. (2019) Pleomorphic Adenoma: A Rare Presentation in Buccal Salivary Gland with Extensive Squamous and Mucous Metaplasia. The Pan African Medical Journal, 26, 147. https://doi.org/10.11604/pamj.2019.33.147.17550

[25] Devgan, M. and Devgan, B.K. (1977) Epidermal Inclusion Cyst in Pleomorphic 
Adenoma (Mixed Parotid Tumor). Ear, Nose, \& Throat Journal, 56, 75-77.

[26] Hamdan, K., Maly, B., Elashar, R. and Gross, M. (2005) Mucinous and Squamous Metaplasia in Benign Tumors of the Parotid Gland: A Potential Pitfall in the Diagnosis. Otolaryngology-Head and Neck Surgery, 133, 987-988.

https://doi.org/10.1016/j.otohns.2005.01.020

[27] Lucas, R.B. (1972) Pathology of Tumors of the Oral Tissues. 2nd Edition, Churchill Livingstone, London.

[28] El-Naggar, A.K., Chan, J.K.C., Grandis, J.R., Takata, T. and Slootweg, P.J. (2017) WHO Classification of Head and Neck Tumours. World Health Organization Classification of Tumours. IARC Press, Lyon.

[29] Kapadia, S.B., Dusenbery, D. and Dekker, A. (1997) Fine Needle Aspiration of Pleomorphic Adenoma and Adenoid Cystic Carcinoma of Salivary Gland Origin. Acta Cytological, 41, 487-492. https://doi.org/10.1159/000332543

[30] Viguer, J.M., Vicandi, B., Jiménez-Heffernan, J.A., López-Ferrer, P. and Limeres, M.A. (1997) Fine Needle Aspiration Cytology of Pleomorphic Adenoma. An Analysis of 212 Cases. Acta Cytological, 41, 786-794. https://doi.org/10.1159/000332705

[31] Compagno, J. and Wong, R.T. (1977) Intranasal Mixed Tumors (Pleomorphic Adenomas): A Clinicopathologic Study of 40 Cases. American Journal of Clinical Pathology, 68, 213-218. https://doi.org/10.1093/ajcp/68.2.213

[32] Khandekar, S., Dive, A., Munde, P. and Wankhede, N.D. (2015) Pleomorphic Adenoma of the Buccal Salivary Gland. Journal of Oral and Maxillofacial Pathology, 19, 111. https://doi.org/10.4103/0973-029X.157222

[33] Sharma, A., Deshmukh, S., Shaikh, A. and Dabholkar, J. (2013) Pleomorphic Adenoma of the Minor Salivary Gland of the Cheek. Singapore Medical Journal, 54, e183-e184. https://doi.org/10.11622/smedj.2013180 